\title{
Egas Moniz e a neurocirurgia brasileira
}

\author{
Guilherme Cabral Filho, Sebastião Gusmão, Roberto Leal Silveira
}

\section{RESUMO}

Relata-se a trajetória científica de Egas Moniz com ênfase em suas relações com a neurocirurgia brasileira.

\section{PALAVRAS-CHAVE}

História da medicina. Angiografia cerebral. Leucotomia pré-frontal.

\author{
ABSTRACT \\ Egas Moniz and the Brazilian neurosurgery \\ impact on Brazilian neurosurgery. \\ KEYWORDS \\ History. Cerebral angiography. Prefrontal leucotomy.
}

This work presents a summary of the scientific career of Egas Moniz with an emphasis on his

No ano de 2000, realizou-se no Brasil a primeira reunião da recém-fundada Sociedade de Neurocirurgia de Língua Portuguesa e comemoraram-se os 500 anos da viagem de Pedro Álvares Cabral. Julgamos pertinente resumir nossas relações com o ilustre lusitano, Egas Moniz (1874-1955), outro desbravador de "mares nunca dantes navegados" (Figura 1).

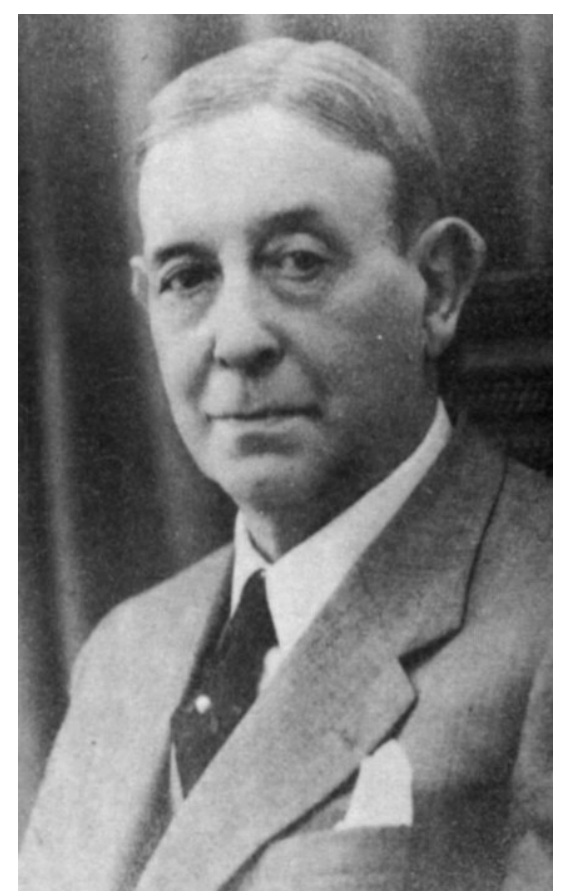

Figura 1 - Egas Moniz (1874-1955).
A atribuição, em 1949, do Prêmio Nobel de Fisiologia e Medicina ao Professor de Neurologia da Faculdade de Medicina da Universidade de Lisboa, Egas Moniz, tornou-o o maior nome das ciências médicas em língua portuguesa. Apesar de ter sido neurologista, está tão ligado à neurocirurgia que, segundo Foester, "o nome de Egas Moniz deve ser posto ao lado do de Cushing e de Dandy entre os que mais contribuíram para o progresso da cirurgia do sistema nervoso"6. Em virtude dos vínculos entre Portugal e Brasil, essa ligação se estende à neurocirurgia brasileira, a ser evidenciada em seguida, no breve relato da trajetória científica do cientista português.

Egas Moniz graduou-se pela Faculdade de Medicina da Universidade de Coimbra em 1899. Fez sua formação neurológica na França. Primeiro, em Bordéus, com Pitres e, depois, em Paris, com Pierre Marie, Déjerine e Babinski. Assumiu, em 1911, a recém-criada Cátedra de Neurologia da Faculdade de Medicina da Universidade de Lisboa ${ }^{6,7}$.

Depois de pesquisas em animais e cadáveres humanos, Egas Moniz, com a ajuda do neurocirurgião Almeida Lima (1903-1985), injetou pela primeira vez, em 28 de junho de 1927, na artéria carótida humana, uma solução de iodeto de sódio a $25 \%$, com o objetivo de contrastar radiograficamente os vasos cerebrais e assim localizar os tumores intracranianos ${ }^{3,6,7}$. Os prolongados trabalhos preliminares em animais foram realizados no Instituto Rocha Cabral (Figura 2), onde lhe foram proporcionadas todas as facilidades de pesquisa. Esse 


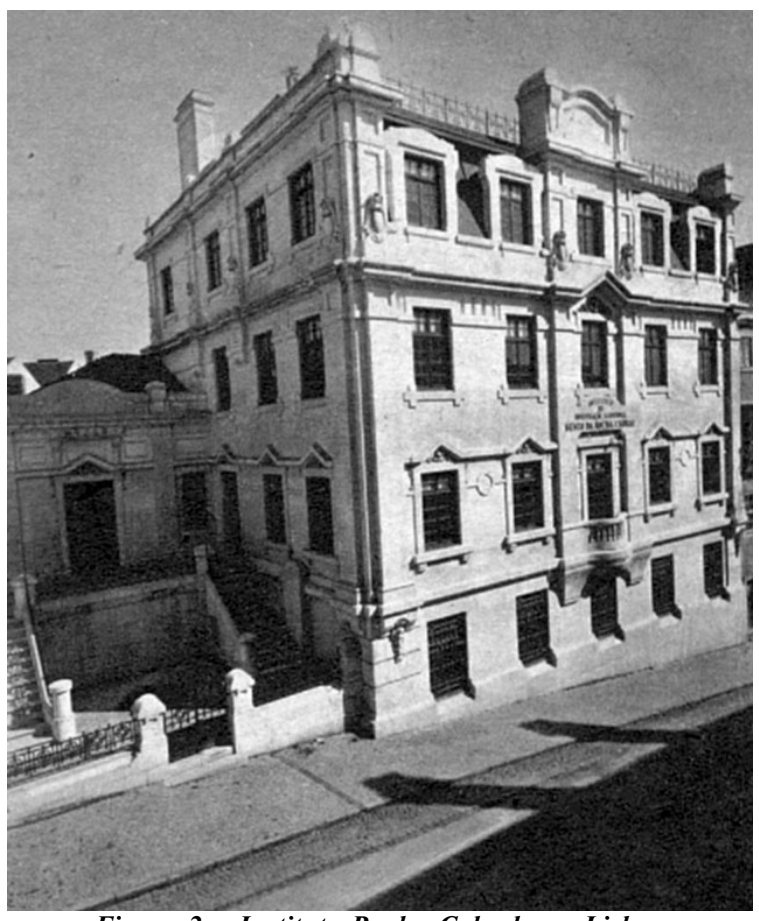

Figura 2 - Instituto Rocha Cabral, em Lisboa.

instituto foi criado pelo português Bento Rocha Cabral, que edificou um rico patrimônio no Rio de Janeiro e é tio-avô do primeiro autor deste trabalho. A angiografia cerebral causou verdadeira revolução no diagnóstico das lesões encefálicas e assegurou o reconhecimento internacional a seu autor.

O governo brasileiro, por intermédio de Aloysio de Castro, então professor da Faculdade de Medicina do Rio de Janeiro e Diretor do Departamento Nacional de Ensino, convidou Egas Moniz a visitar o Brasil. A finalidade da visita era realizar conferências e demonstrações de sua recente descoberta ${ }^{6}$.

Egas Moniz chegou ao Brasil em primeiro de agosto de 1928, o ano crucial da neurocirurgia brasileira. Nesse ano, Brandão Filho (1881-1957) encontrava-se no auge de sua tentativa de tratamento cirúrgico dos tumores cerebrais. Antônio Austregésilo visitava os serviços de neurocirurgia dos Estados Unidos e, de regresso, convocaria Alfredo Monteiro e José Ribe Portugal para o início da neurocirurgia brasileira como especialidade.

Augusto Brandão Filho foi professor de Clínica Cirúrgica da Faculdade Nacional de Medicina da Universidade do Brasil, tendo ocupado também sua direção. Exerceu sua atividade cirúrgica no Hospital da Misericórdia, no Rio de Janeiro. Foi um dos mais hábeis cirurgiões de seu tempo e dotado de alto espírito científico. Era denominado o Príncipe da Cirurgia Brasileira. Merece também o título de precursor da neurocirurgia no Brasil. Foi o primeiro cirurgião brasileiro a ir além da cirurgia do trauma e tentar o tratamento cirúrgico dos tumores cerebrais.
Brandão Filho foi, também, pioneiro dos exames neurorradiológicos em nosso país. Foi o primeiro a realizar no Brasil a ventriculografia e a angiografia cerebral ${ }^{1,2}$. Na realização desses exames, contou com a colaboração de dois grandes vultos da medicina. Na ventriculografia foi ajudado por Manoel de Abreu (1894-1962), futuro inventor, em 1936, da fotografia da imagem fluoroscópica, conhecida como abreugrafia. Na angiografia cerebral foi auxiliado por Egas Moniz, como relata este em Confidências de um Investigador Científico ${ }^{6}$ : “... o professor Brandão Filho realizou na Santa Casa a primeira prova de encefalografia arterial, com grande assistência de médicos e estudantes, e que foi feliz. A doente nada sofreu e o filme arteriográfico foi regular".

Tal feito foi comunicado à Academia Nacional de Medicina, na sessão de 18 de outubro de 1928. O exame foi realizado em paciente internada no Hospital da Misericórdia do Rio de Janeiro, que se apresentava com cefaléia, amaurose progressiva, oftalmoplegia direita e crises convulsivas. Eis o relato do próprio Brandão Filho²:

"Primeira encefalografia arterial (em 6 de agosto de 1928) - Lado direito. Éter. Incisão de cinco centímetros ao longo dos vasos. Isolamento da carótida primitiva até a sua bifurcação. Isolamento da carótida externa. Transporte da doente para o Gabinete de Radiografia. Laqueação da carótida externa e da primitiva. Picada de carótida primitiva com agulha curva de $1 \mathrm{~mm}$ de calibre. Injeção de pouco mais de $5 \mathrm{~cm}^{3}$ de soluto de iodeto de sódio a $25 \%$. A velocidade de injeção obedeceu a andamento previamente estabelecido pelo Prof. Egas Moniz. Impressão da chapa fotográfica à passagem do quinto centímetro cúbico, sob o comando do citado mestre lusitano. Exposição de 0,2 de segundo.

A prova radiográfica deu excelente resultado, sendo considerado pelo autor do método como uma das melhores até então obtidas, não obstante o tempo de exposição ter sido o dobro do aconselhado. As figuras 108 e 109 (figuras 3 e 4 no presente texto) representam com nitidez o resultado alcançado.

O Sr. Prof. Egas Moniz examinou cuidadosamente a prova e nada de anormal encontrou, razão pela qual pediu que fosse praticada mais tarde prova semelhante do lado oposto.

Segunda encefalografia arterial (em 2 de outubro de 1928) - Achando-se ausente o sábio mestre português, coube-me, com os Drs. Teixeira Mendes e Duque Estrada, a realização da segunda encefalografia, cuja técnica obedeceu ponto por ponto à norma adotada na primeira arteriografia.

As pinças de Martins empregadas para a laqueação das carótidas foram-nos gentilmente oferecidas pelo Prof. Egas Moniz a quem mais uma vez agradecemos de todo coração. 


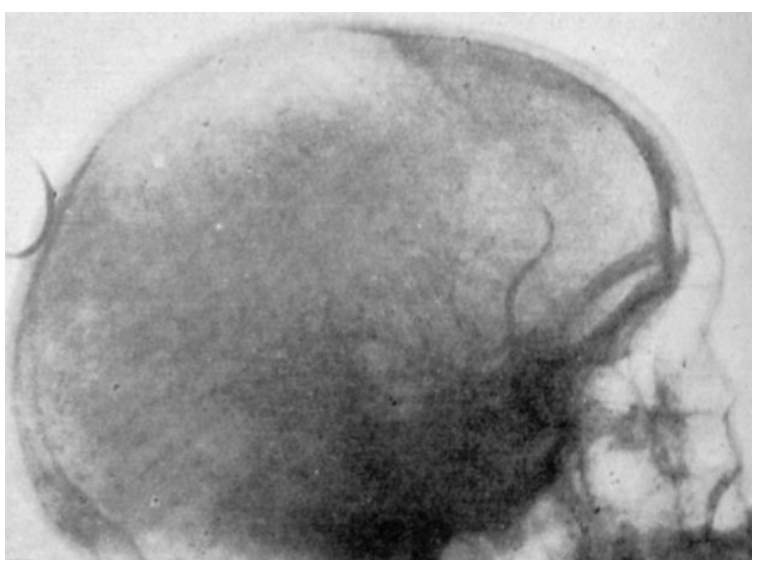

Figura 3 - Primeira angiografia cerebral realizada no Brasil; imagem lateral, lado direito.

O soluto de iodeto de sódio a $25 \%$ foi cuidadosamente preparado pelo competente farmacêutico Paulo Seabra, que também teve a bondade de examiná-lo, momentos antes de seu uso, para constatar a pureza do preparado.

A prova obteve bom resultado, conforme se verifica nas figuras 110 e 111 . Digna de referência especial, apenas uma incurvação, de concavidade voltada para cima, de uma artéria do grupo silviano.

Os resultados foram enviados ao Prof. Egas Moniz, já então em Lisboa, para que interpretasse os filmes." Eis a resposta enviada ao Dr. Teixeira Mendes:

"Meu prezado colega e amigo,

Antes de mais nada, permita que os felicite, a si e ao Prof. Brandão, da excelente arteriografia que obtiveram. Estão senhores da técnica e perderam o receio, que ainda existe em alguns centros da Europa, em executar a prova da encefalografia. O colega Dr. Estrada é precioso auxiliar com que podem contar. Falemos agora da interpretação dos filmes. Comparando o que aí tiramos, quando tive a ventura de os visitar, e que supondo ter sido à direita com o de agora à esquerda, noto que há um pequeno abaixamento na origem do grupo silviano, sem deformação do sifão carotídeo, à direita. É pouco, mas deixaria a suspeita (não mais que isso) de uma pequena neoplasia frontal desse lado. Sendo apenas uma suspeita, vigiaria a sintomatologia nesse sentido para uma intervenção futura, a não ser que a perda precipitada da visão impusesse uma intervenção imediata.

Tenho agora notado, nos casos injetados, uma melhora acentuada da sintomatologia hipertensiva após as injeções do iodeto de sódio. A cefaléia especialmente diminui consideravelmente e a visão também melhora por vezes, embora sejam benefícios transitórios. Alguns porém têm-se conservado. Ando a reunir casos. Amanhã faremos a sétima prova deste mês. Vamos a

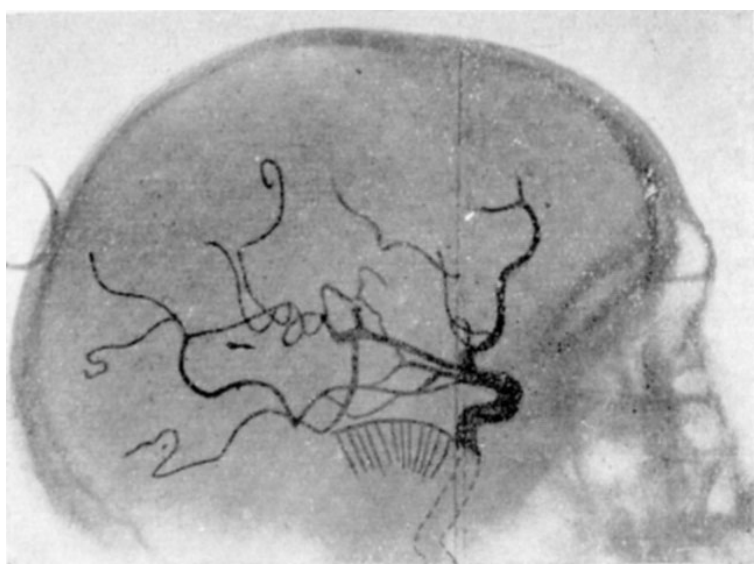

Figura 4 - Primeira angiografia cerebral realizada no Brasil; imagem lateral, lado direito.

ver os resultados desta série, pois tenho um grande número de casos entre-mãos.

Do que aí forem fazendo mande dizer e lembra-me muito ao Prof. Brandão Filho, de quem conservo a melhor recordação, e ao Dr. Estrada, exímio radiologista".

No período de 1 a 6 de agosto de 1928, Egas Moniz realizou, no Rio de Janeiro, quatro conferências sobre a angiografia cerebral. Em 15 desse mês, partiu para São Paulo, onde também realizou duas conferências sobre a angiografia cerebral e orientou o cirurgião Ayres Neto, em 17 de agosto, a realizar uma angiografia cerebral.

De retorno ao Rio de Janeiro, foi recebido, em 22 de agosto, no Palácio de Catete, pelo Presidente da República, Washington Luís. Retornou a Portugal em 24 de agosto de 1928. Em sua obra Confidências de um Investigador Científico ${ }^{6}$, relata em pormenores sua estada no Brasil e assinala os laços de amizade que o prendia a vários médicos brasileiros. Realizou, inclusive, trabalho biográfico sobre Afrânio Peixoto5 .

Em dezembro de 1935, sob a orientação de Egas Moniz, Almeida Lima realizou a primeira leucotomia préfrontal, método de tratamento dos distúrbios mentais, por meio de secções parciais da substância branca do lóbulo pré-frontal. Esse procedimento abriu novo campo na neurocirurgia, a psicocirurgia. Em 1936, Egas Moniz publicou os dados sobre os primeiros 20 pacientes operados ${ }^{4}$. Neste mesmo ano, Aloysio de Mattos Pimenta (1912-1987) executou a primeira leucotomia préfrontal no Brasil e nas Américas. Este pioneiro da neurocirurgia na Escola Paulista de Medicina iniciou sua atividade médica no Hospital Psiquiátrico do Juqueri, onde adquiriu grande experiência com a leucotomia pré-frontal. Esse nosocômio foi visitado por Egas Moniz em 17 de agosto de 1928, sendo recebido por seu diretor, Pacheco e Silva ${ }^{6}$. 
A grande projeção internacional de Egas Moniz fez com que Lisboa fosse escolhida como sede do Congresso Internacional de Psicocirurgia, em agosto de 1948. Nessa reunião, ocorreu significativa participação de psiquiatras e neurocirurgiões brasileiros, que apresentaram vários trabalhos sobre leucotomia pré-frontal. Mattos Pimenta apresentou sua extensa experiência em três trabalhos, sendo a seguinte a introdução do primeiro trabalho: "Mattos Pimenta foi um dos primeiros cirurgiões que pôs em prática o método de Egas Moniz, tendo operado os primeiros doentes em 1936. De então até a data, operou 161 doentes segundo a técnica de Egas Moniz, 48 segundo Freeman e Watts e em 70 usou a técnica em três tempos" 6 .

$\mathrm{Na}$ sessão de encerramento, os membros da delegação brasileira (Pacheco e Silva, Paulino Longo, Mattos Pimenta, Mário Yahn, Aníbal Silveira, Élio Simões e Antonio Carlos Barreto) tiveram a iniciativa, partida de Paulino Longo (iniciador e professor de neurologia da Escola Paulista de Medicina e quem estimulou Mattos Pimenta a implantar o Serviço de Neurocirurgia no Hospital São Paulo), de encaminhar à mesa a seguinte moção:

"Os membros da Primeira Conferência Internacional da Psicocirurgia, a qual aderiram 27 países diferentes, considerando os inestimáveis serviços prestados à Ciência e à humanidade pelas duas notáveis descobertas do Prof. Egas Moniz, representadas pela arteriografia e leucotomia cerebrais, hoje universalmente consagradas, resolvem, na sua sessão de encerramento, sugerir às associações médicas dos diversos países que compareceram à conferência de Lisboa a apresentação do nome do insigne cientista português como digno por todos os títulos à candidatura ao prêmio Nobel de Medicina" ${ }^{6}$.
A idéia foi apoiada com entusiasmo pelos membros das delegações estrangeiras. Egas Moniz recebeu o Prêmio Nobel de Fisiologia e Medicina em 1949 pela leucotomia pré-frontal e "por ter aberto caminhos inesperados para novos conhecimentos sobre o encéfalo e suas relações com a personalidade humana". Foi o primeiro e único representante de países de língua portuguesa a receber o Prêmio Nobel, até que José Saramago o recebesse em literatura.

\section{Referências}

1. BRANDÃO FILHO A: Quisto da hipófise; ventriculografia e intervenção cirúrgica por via frontal. Jornal dos Clínicos 16:224-51, 1924.

2. BRANDÃO FILHO A: Clínica cirúrgica. Rio de Janeiro, Editora Scientífica, 1930, vol 4.

3. MONIZ E: L'encéphalographie artérielle, son importance dans la localization des tumeurs cérébrales. Rev Neurol 1:72-90, 1927.

4. MONIZ E: Tentatives opératoires dans le traitement de certaines psychoses. Paris, ed. Masson, 1936.

5. MONIZ E: Afrânio Peixoto (Notas Biográficas e Panegírico). Lisboa, Medicina Contemporânea, 1947.

6. MONIZ E: Confidências de um investigador científico. Lisboa, Edições Ática, 1949.

7. FERNANDES B: Egas Moniz, pioneiro de descobrimentos médicos. Lisboa, Biblioteca Breve, 1983.

Original recebido em março de 2000

Aceito para publicação em junho de 2000

Endereço para correspondência:

Sebastião Gusmão

Rua Padre Rolim, 921/21

CEP 30130-090 - Belo Horizonte, MG 